\title{
Direct Surgical Treatment of Giant Middle Cerebral Artery Aneurysms Using Microvascular Reconstruction Techniques
}

\author{
Hideki NAKAJIMA, ${ }^{1}$ Hiroyasu KAMIYAMA, ${ }^{1}$ Toshitaka NAKAMURA, ${ }^{1}$ \\ Katsumi TAKIZAWA, ${ }^{1}$ Joji TOKUGAWA, ${ }^{1}$ and Kenji OHATA ${ }^{2}$
}

\author{
${ }^{1}$ Department of Neurosurgery, Asahikawa Red Cross Hospital, Asahikawa, Hokkaido; \\ ${ }^{2}$ Department of Neurosurgery, Osaka City University Graduate School of Medicine, Osaka, Osaka
}

\begin{abstract}
Giant intracranial aneurysm is a life-threatening lesion and treatment of the aneurysm could be hazardous and complex. This study describes direct surgical treatment of giant middle cerebral artery (MCA) aneurysms using microvascular reconstruction techniques in 13 patients treated between 2006 and 2009. In all 13 patients, superficial temporal artery (STA)-MCA $\left(M_{2}\right)$ anastomosis was performed as a precaution prior to attacking the aneurysm. During surgery, microvascular reconstruction of incorporative arteries was additionally performed if the aneurysm was removed. Direct neck clipping was performed in four patients, trapping and removal of the aneurysm in one, and removal of the aneurysm with vascular reconstruction of the MCA in eight patients. Minor ischemic complications due to perforator ischemia were recognized in 6 patients, and 10 patients achieved functionally favorable outcomes (modified Rankin scale score 0 or 1). In direct surgery for giant MCA aneurysm, precautionary STA-M bypass could provide appropriate surgical strategies tailored to individual cases, including direct clipping and removal of the aneurysm with or without vascular reconstruction. Microvascular reconstruction techniques are essential for complete cure of giant MCA aneurysms.
\end{abstract}

Key words: giant intracranial aneurysm, middle cerebral artery, direct surgery, bypass surgery, perforator ischemia

\section{Introduction}

Giant intracranial aneurysm, with maximum diameter of $25 \mathrm{~mm}$ or larger, is a life-threatening lesion with a mortality rate of $65-85 \%$ within 2 years. ${ }^{3,5,6,13,14)}$ Giant intracranial aneurysm should be treated aggressively considering the grave natural history, but sometimes the treatment can be hazardous and complex. Several cases of the treatment of giant middle cerebral artery (MCA) aneurysms have been attempted, but were not always successful. . $^{1,2,4,7,8,10,12,15-25)}$ The appropriate treatment should be selected according to the characteristics of each aneurysm. This study reviewed the treatment of our series of giant MCA aneurysms.

\section{Materials and Methods}

A total of 1232 aneurysms were treated with direct surgery at the Asahikawa Red Cross Hospital between 2006 and 2009. Of these, 13 were giant MCA aneurysms (Table 1). None of the patients, 5 males and 8 females aged 14 to 77 years (mean 42.4 years), had received previous treatment for aneurysm. The clinical characteristics are shown in Table 2. The aneurysm diameter was $25-50 \mathrm{~mm}$ (mean $33.1 \mathrm{~mm}$ ) on imaging. The aneurysms were saccular in six, thrombosed in four, fusiform in one, and serpentine in two patients. Ten patients presented with no symptom, two with subarachnoid hemorrhage, and one with convulsion.

All aneurysms were treated through frontotemporal craniotomy followed by the distal transsylvian approach. Superficial temporal artery (STA)-MCA $\left(\mathrm{M}_{2}\right)$ single or double anastomosis was performed

Received June 16, 2011; Accepted September 22, 2011

Author's present address: H. Nakajima, MD, Department of Neurosurgery, Osaka City General Hospital, Osaka, Japan. 
Table 1 Summary of giant middle cerebral artery aneurysms

\begin{tabular}{|c|c|c|c|c|c|c|c|c|}
\hline $\begin{array}{l}\text { Case } \\
\text { No. }\end{array}$ & $\begin{array}{l}\text { Age } \\
\text { (yrs) } / \\
\text { Sex }\end{array}$ & Side & $\begin{array}{l}\text { Size } \\
(\mathrm{mm})\end{array}$ & Shape & Onset & Treatment & Complication & $\mathrm{mRS}$ \\
\hline 2 & $69 / \mathrm{F}$ & $\mathrm{L}$ & 25 & saccular & incidental & removal of aneurysm (trapping) & none & 0 \\
\hline 3 & $77 / \mathrm{F}$ & $\mathrm{R}$ & 25 & saccular & incidental & clipping & none & 0 \\
\hline 5 & $57 / \mathrm{M}$ & $\mathrm{L}$ & 35 & saccular & $\mathrm{SAH}(\mathrm{H} \& \mathrm{~K} 3)$ & clipping & none & 0 \\
\hline 6 & $43 / F$ & $\mathrm{R}$ & 35 & saccular & SAH (H\&K 4) & clipping & $\begin{array}{l}\text { perforator } \\
\text { ischemia }\end{array}$ & 3 \\
\hline 7 & $48 / \mathrm{F}$ & $\mathrm{L}$ & 50 & thrombosed & incidental & $\begin{array}{l}\text { removal of aneurysm with } \mathrm{M}_{1}-\mathrm{M}_{2} \\
\text { reanastomosis }\end{array}$ & none & 0 \\
\hline 8 & $15 / F$ & $\mathrm{~L}$ & 35 & thrombosed & incidental & $\begin{array}{l}\text { removal of aneurysm with } \\
\text { complex vascular reconstruction } \\
\text { including a perforator }\end{array}$ & $\begin{array}{l}\text { perforator } \\
\text { ischemia }\end{array}$ & 2 \\
\hline 10 & $54 / \mathrm{F}$ & $\mathrm{R}$ & 25 & thrombosed & incidental & $\begin{array}{l}\text { removal of aneurysm with } \mathrm{M}_{1}-\mathrm{M}_{2} \\
\text { reanastomosis }\end{array}$ & $\begin{array}{l}\text { perforator } \\
\text { ischemia }\end{array}$ & 3 \\
\hline 11 & $14 / \mathrm{M}$ & $\mathrm{R}$ & 30 & fusiform & incidental & $\begin{array}{l}\text { removal of aneurysm with } \\
\text { complex vascular reconstruction } \\
\text { including a perforator }\end{array}$ & $\begin{array}{l}\text { perforator } \\
\text { ischemia }\end{array}$ & 1 \\
\hline 12 & $35 / \mathrm{M}$ & $\mathrm{R}$ & 25 & serpentine & incidental & $\begin{array}{l}\text { removal of aneurysm with } \mathrm{M}_{1}-\mathrm{M}_{2} \\
\text { reanastomosis }\end{array}$ & none & 0 \\
\hline 13 & $34 / F$ & $\mathrm{R}$ & 25 & serpentine & incidental & $\begin{array}{l}\text { removal of aneurysm with } \mathrm{M}_{1}-\mathrm{M}_{2} \\
\text { reanastomosis }\end{array}$ & none & 0 \\
\hline
\end{tabular}

F: female, H\&K: Hunt and Kosnik, L: left, M: male, mRS: modified Rankin scale, R: right, SAH: subarachnoid hemorrhage.

with 10-0 nylon sutures as a precaution prior to approaching the aneurysm. Direct neck clipping was the first option. Unclippable aneurysm was trapped and removed, then $\mathrm{M}_{1}-\mathrm{M}_{2}$ reanastomosis was performed with 9-0 nylon sutures. For aneurysms incorporated with multiple $\mathrm{M}_{2}$ branches, complex microvascular reconstruction was performed. Furthermore, reconstruction of a perforator was carried out with 11-0 nylon for aneurysms incorporated with perforators. These procedures were done under intraoperative motor evoked potential (MEP) monitoring in seven cases.

\section{Results}

Direct neck clipping was performed in four patients, trapping and removal of the aneurysm in one, removal of the aneurysm with $\mathrm{M}_{1}-\mathrm{M}_{2}$ reanastomosis in five, and removal of the aneurysm with complex vascular reconstruction of the MCA including the incorporated perforator in three patients (Table 2). Reconstruction of the perforator was performed in three patients (Cases 1, 8, and 11), and anticoagulant and antiplatelet agents were administered intra- and postoperatively in these patients.

Minor ischemic complications caused by perforat- ing artery injuries were recognized in six patients, asymptomatic in one and manifesting as only hemiparesis in five. We speculate that reconstruction of a perforator might not be finished in time and transient trapping of the aneurysm might include a perforator. Permanent neurological deficits persisted in four patients. No complication other than perforating artery ischemia was recognized in all patients, and 10 patients had functionally favorable outcomes (modified Rankin scale score 0 or 1) (Table 2).

Magnetic resonance (MR) imaging including diffusion-weighted imaging was performed immediately after surgery in all patients and revealed perforator ischemia in six patients. Three-dimensional computed tomography (3DCT) angiography or cerebral angiography was performed within 7 days after the surgery. 3DCT angiography and/or MR imaging were performed every 6 months for long-term follow-up study. The aneurysms were not visualized in any of the patients throughout the course of follow up. All $\mathrm{M}_{1}-\mathrm{M}_{2}$ reanastomoses and all STA-MCA anastomoses for stump $\mathrm{M}_{2}$ remained patent, but evaluation of complex vascular reconstruction was difficult.

Intraoperative MEP monitoring was used in seven 
Table 2 Clinical characteristics of the patients

\begin{tabular}{lc}
\hline Baseline characteristics & \\
General & \\
mean age (range), yrs & $42.4(14-77)$ \\
female sex & $8(62 \%)$ \\
Aneurysm & \\
left side & $5(38 \%)$ \\
mean diameter (range), mm & $33.1(25-50)$ \\
saccular & $6(46 \%)$ \\
thrombosed & $4(31 \%)$ \\
fusiform & $1(8 \%)$ \\
serpentine & $2(15 \%)$ \\
Onset & \\
incidental & $10(77 \%)$ \\
SAH & $2(15 \%)$ \\
convulsion & $1(8 \%)$ \\
Treatment & \\
clipping & $4(31 \%)$ \\
removal of aneurysm (trapping) & $1(8 \%)$ \\
removal of aneurysm with $\mathrm{M}_{1}$ - $\mathrm{M}_{2}$ reanastomosis & $5(38 \%)$ \\
removal of aneurysm with complex vascular & $3(23 \%)$ \\
reconstruction including a perforator & \\
Results & \\
Complication & \\
minor ischemic stroke & $6(46 \%)$ \\
Functional outcome (mRS) & \\
0 & $9(69 \%)$ \\
1 & $1(8 \%)$ \\
2 & $1(8 \%)$ \\
4 & $2(15 \%)$ \\
5 & $0(0 \%)$ \\
\hline & $0(0 \%)$ \\
\hline
\end{tabular}

SAH: subarachnoid hemorrhage, mRS: modified Rankin scale.

Table 3 Summary of cases with intraoperative motor evoked potential (MEP) monitoring

\begin{tabular}{clccc}
\hline Case No. & Final MEP & $\begin{array}{c}\text { Perforator } \\
\text { ischemia }\end{array}$ & $\begin{array}{c}\text { Postoperative } \\
\text { hemiparesis }\end{array}$ & mRS \\
\hline 1 & recovered & + & mild & 0 \\
7 & recovered & - & none & 0 \\
8 & disappeared & + & severe & 2 \\
9 & recovered & + & none & 0 \\
11 & recovered & + & mild & 1 \\
12 & recovered & - & none & 0 \\
13 & recovered & - & none & 0 \\
\hline
\end{tabular}

mRS: modified Rankin scale.

cases (Cases 1, 7, 8, 9, 11, 12, and 13). Final intraoperative MEP and postoperative course are summarized in Table 3. Perforator ischemia was detected even in patients with recovered final intraoperative MEP, but these patients had functionally favorable outcomes.

Representative Case 1: A 23-year-old woman with no neurological deficits was incidentally found to
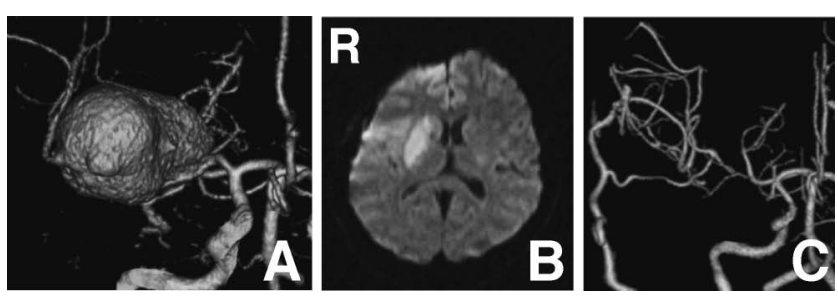

Fig. 1 Case 1. A: Preoperative three-dimensional computed tomography (3DCT) angiogram, anteroposterior view, showing a giant saccular right middle cerebral artery (MCA) aneurysm, $40 \mathrm{~mm}$ in maximum diameter. B: Postoperative axial diffusion-weighted magnetic resonance image showing fresh infarction in the right basal ganglia. C: Postoperative 3DCT angiogram, anteroposterior view, not visualizing the giant MCA aneurysm.

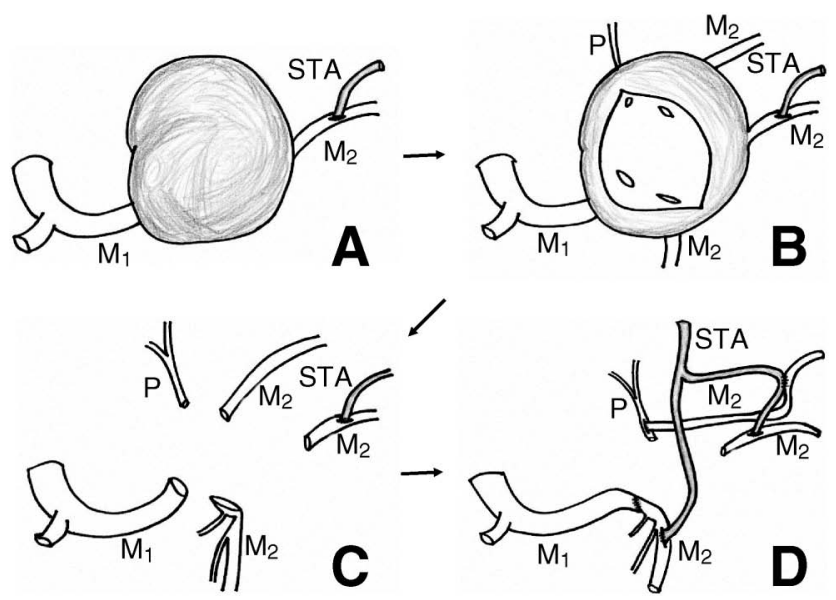

Fig. 2 Intraoperative illustrations in Case 1. A: Superficial temporal artery (STA)- $M_{2}$ anastomosis was performed. B: Aneurysm was incised and the branches including the perforator $(P)$ were confirmed from inside the aneurysm. C: Aneurysm was removed. D: Complex vascular reconstruction was completed with five anastomoses: double STA-M $\mathrm{M}_{2}$ end-to-side anastomosis, $M_{1}-M_{2}$ end-to-end anastomosis, STA-M $M_{2}$ side-to-side anastomosis, and $\mathrm{M}_{2}$-peforator end-to-side anastomosis.

have a giant saccular aneurysm on the right MCA, $40 \mathrm{~mm}$ in maximum diameter (Fig. 1A). Removal of the aneurysm was planned under intraoperative MEP monitoring, as shown in Fig. 2. Part of the aneurysm appeared as soon as the sylvian fissure was opened. STA-MCA single anastomosis was performed prior to exposing the aneurysm to secure the cortical blood flow. The aneurysm was so large that incision was required to confirm any branches on the blind side. The aneurysm was temporarily trapped and the aneurysm wall was cut with a 

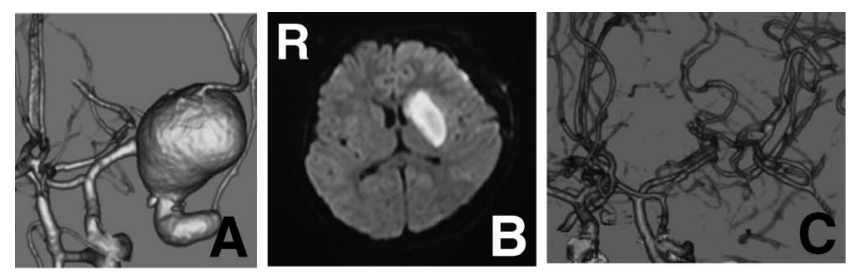

Fig. 3 Case 8. A: Preoperative three-dimensional computed tomography (3DCT) angiogram, anteroposterior view, showing a giant partially thrombosed left middle cerebral artery (MCA) aneurysm, with a maximum diameter of $35 \mathrm{~mm}$. B: Postoperative axial diffusionweighted magnetic resonance image showing fresh infarction in the left basal ganglia. C: Postoperative 3DCT angiogram, anteroposterior view, not visualizing the giant MCA aneurysm.

monopolar coagulator. The presence of any perforating artery was confirmed from inside the aneurysm near the proximal neck and then the aneurysm was removed. Finally, complex vascular reconstruction was completed of the MCA with additional STA-MCA anastomosis including reconstruction of the perforator, and detection of MEP was confirmed. Postoperative diffusion-weighted imaging showed perforator territory ischemia (Fig. 1B), but she had a functionally favorable outcome and is now working at an office. The aneurysm had disappeared completely on follow-up imaging 2 years after the surgery (Fig. 1C).

Representative Case 8: A 15-year-old woman with no neurological deficits was incidentally found to have a giant partially thrombosed aneurysm of the left MCA, with a maximum diameter of $35 \mathrm{~mm}$ (Fig. 3A). Surgery was performed under intraoperative MEP monitoring, as shown in Fig. 4. After precautionary STA-MCA bypass was performed, the $\mathrm{M}_{1}$ portion was temporarily clipped. After the aneurysm was incised to confirm the branches from the inner wall, the MEP waves disappeared, so rapid reperfusion of the artery was essential. A perforator branching from the aneurysm wall required reconstruction with an STA patch $\left(\mathrm{M}_{1}\right.$-perforator end-toend anastomosis with STA patch). Regrettably, MEP did not recover until the end of the surgery. Postoperative MR imaging showed perforator territory ischemia (Fig. 3B) and the patient had severe hemiparesis. However, the patient is now walking with a T-cane after rehabilitation. The aneurysm had disappeared completely on follow-up imaging 1 year after the surgery (Fig. 3C).

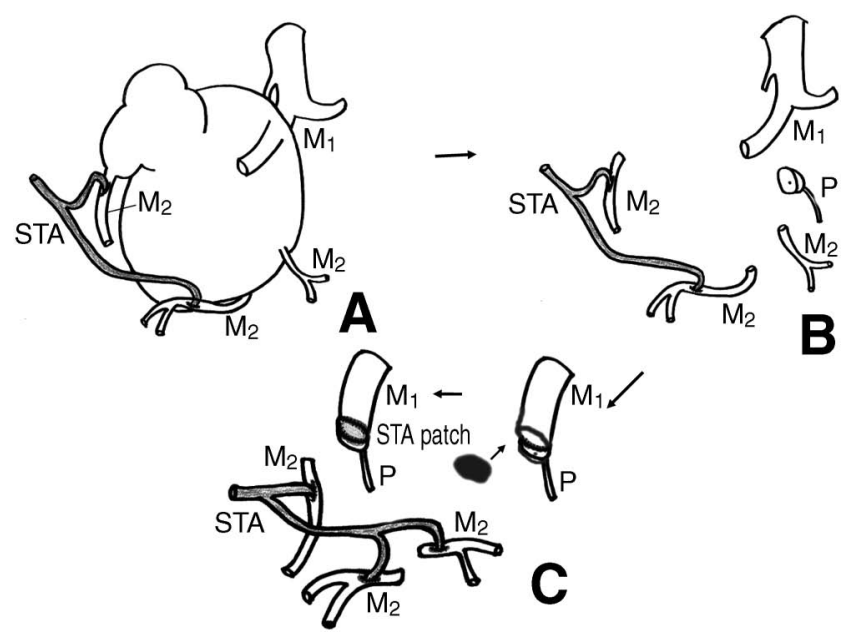

Fig. 4 Intraoperative illustrations in Case 8. A: Double superficial temporal artery (STA)- $M_{2}$ anastomosis was carried out. B: Aneurysm was removed and the perforator $(P)$ branching off from the aneurysm wall was confirmed. C: After another STA-M $M_{2}$ anastomosis was completed, reconstruction of the perforator was performed with a STA patch $\left(M_{1}\right.$-perforator end-to-end anastomosis with STA patch).

\section{Discussion}

We could obtain favorable outcomes after the direct surgery of giant MCA aneurysms using microvascular reconstruction techniques before and after direct intervention to treat the lesions during surgery. Precautionary STA-MCA bypass may prevent possible ischemic events during necessary temporary clipping, and further vascular reconstruction of the stumps of incorporated MCA branches may restore the blood flow. Advanced anastomosis techniques are recommended for the treatment of giant MCA aneurysms.

A significant number of smaller series or case reports have described the treatment of giant MCA aneurysms. ${ }^{1,2,4,7,8,10,12,15-25)}$ A few experienced surgeons have included patients with giant MCA aneurysms in larger series of cerebral revascularization, ${ }^{6,9,11,17)}$ but these cases were not described separately. Giant MCA aneurysms were treated with a flow replacement bypass. ${ }^{25)}$ The excimer laser-assisted nonocclusive anastomosis technique was used on 22 patients, and specific bypasses were described in detail. Endovascular coiling with extracranial-intracranial bypass was used for giant MCA aneurysms, ${ }^{20)}$ and preservation of incorporated branches was discussed. Neither study mentioned anything about perforator ischemia. We believe that perforator ischemia is an unavoidable problem for 
complete cure of giant MCA aneurysms, but this has never been discussed in the previous literature.

Preservation of the blood flow in both the cortical and perforating artery territories is a difficult issue for the treatment of large/giant MCA aneurysms. Precautionary STA-MCA bypass may save peripheral cortical blood flow. On the other hand, small caliber perforating arteries such as the lenticulostriate arteries around the aneurysm cannot be detected on preoperative neuroimaging. Even exposing the aneurysm is unlikely to identify all such vessels. In such cases, simple neck clipping or trapping without meticulous observation around the aneurysm would be harmful.

In the present cases, precautionary STA-MCA bypass was established prior to approaching the aneurysm in all patients, and reconstruction of a perforator was performed after removal of the aneurysm in three cases. Although direct neck clipping was the first option, most of the aneurysms were judged unclippable based on preoperative examinations and intraoperative findings. A resourceful response to emergent intraoperative situations was required according to the character of each aneurysm. Intraoperative MEP was quite useful in such situations, so should be prepared for all direct surgical treatments of giant MCA aneurysms including emergent cases. Detailed preoperative information about incorporated perforators may prevent perforator ischemia in the future.

This series demonstrated that good although not perfect outcomes can be achieved by the surgical treatment of giant MCA aneurysms, despite the potential hazards and complexity. Perforator ischemia is an inevitable problem encountered in the treatment of giant MCA aneurysms and we have to overcome this challenging issue. Only expert neurosurgeons can perform the microvascular reconstruction techniques required, but we believe that these techniques are essential for complete cure of giant MCA aneurysms.

\section{References}

1) Amin-Hanjani $S$, Chen $P R$, Chang SW, Spetzler RF: Long-term follow up of giant serpentine MCA aneurysm treated with EC-IC bypass and proximal occlusion. Acta Neurochir (Wien) 148: 227-228, 2006

2) Ammerman BJ, Smith DR: Giant fusiform middle cerebral aneurysm: Successful treatment utilizing microvascular bypass. Surg Neurol 7: 255-257, 1977

3) Barrow DL, Alleyne C: Natural history of giant intracranial aneurysms and indications for intervention. Clin Neurosurg 42: 214-244, 1955

4) Bushe KA, Bockhorn J: Extracranial-intracranial ar- terial bypass for giant aneurysms. Acta Neurochir (Wien) 54: 107-115, 1980

5) Choi IS, David C: Giant intracranial aneurysms: Development, clinical presentation and treatment. Eur J Radiol 46: 178-194, 2003

6) Drake CG, Peerless SJ: Giant fusiform intracranial aneurysms. Review of 120 patients treated surgically from 1965 to 1992. J Neurosurg 87: 141-162, 1997

7) Fujii K, Fukui M, Matsubara T, Nagata S, Fujiwara S, Matsushima T, Hasuo K: Microsurgical procedures for management of giant middle cerebral aneurysm causing increased intracranial pressure. Surg Neurol 32: 366-371, 1989

8) Greene KA, Anson JA, Spetzler RF: Giant serpentine middle cerebral artery aneurysm treated by extracranial-intracranial bypass. Case report. J Neurosurg 78: 974-978, 1993

9) Hauck EF, Wohlfeld B, Welch BG, White JA, Samson D: Clipping of very large or giant unruptured intracranial aneurysms in the anterior circulation: an outcome study. J Neurosurg 109: 1012-1018, 2008

10) Horowitz MB, Yonas $H$, Jungreis C, Hung TK: Management of a giant middle cerebral artery fusiform serpentine aneurysm with distal clip application and retrograde thrombosis: Case report and review of literature. Surg Neurol 41: 221-225, 1994

11) Lawton MT, Hamilton MG, Morcos JJ, Spetzler RF: Revascularization and aneurysm surgery: Classification schema and management strategies in 68 patients. Neurosurgery 38: 83-94, 1996

12) Lawton MT, Quinones-Hinojosa A: Double reimplantation technique to reconstruct arterial bifurcations with giant aneurysms. Neurosurgery 58 (4 Suppl 2): ONS347-ONS354, 2006

13) O’Shaughnessy BA, Salehi SA, Mindea SA, Batjer $\mathrm{HH}$ : Selective cerebral revascularization as an adjunct in the treatment of giant anterior circulation aneurysms. Neurosurg Focus 14(3): e4, 2003

14) Pia HW, Zierski J: Giant cerebral aneurysms. Neurosurg Rev 5: 117-148, 1982

15) Quinones-Hinojosa A, Lawton MT: Revascularization with saphenous vein bypasses for complex intracranial aneurysms. Skull Base 15: 119-132, 2005

16) Samson DS, Neuwelt EA, Beyer CW, Ditmore QM: Failure of extracranial-intracranial arterial bypass in acute middle cerebral artery occlusion: Case report. Neurosurgery 6: 185-188, 1980

17) Sanai N, Zadar Z, Lawton MT: Bypass surgery for complex brain aneurysms: An assessment of intracranial-intracranial bypass. Neurosurgery 65: 670683, 2009

18) Schonmayr R, Zierski J: Middle cerebral artery revascularization. Neurosurg Rev 6: 25-28, 1983

19) Sekher LN, Kalavakonda C: Saphenous vein and radial artery grafts in the management of skull base tumors and aneurysms, in Schmiedek P (ed): Operative Technique in Neurosurgery. Philadelphia, WB Saunders, 1999, vol 2, pp 129-141

20) Shi ZS, Ziegler J, Duckwiler GR, Jahan R, Frazee J, 
Ausman JI, Martin NA, Vinuela F: Management of giant middle cerebral artery aneurysms with incorporated branches: Partial endovascular coiling or combined extracranial-intracranial bypass-A team approach. Neurosurgery 65(6 Suppl 1): 121-131, 2009

21) Spetzler RF, Chater N: Microvascular bypass surgery. Part 2: Physiological studies. J Neurosurg 45: 508-513, 1976

22) Subdt TM Jr: Surgical technique for giant intracranial aneurysm. Neurosurg Rev 5: 161-168, 1982

23) Suzuki S, Takahashi T, Ohkuma H, Shimizu T, Fujita S: Management of giant serpentine aneurysms of the middle cerebral artery: Review of literature and report of a case successfully treated by STA-MCA anastomosis only. Acta Neurochir (Wien) 117: 23-29, 1992

24) Tognetti F, Andreoli A, Testa C: Giant fusiform aneurysm of the middle cerebral artery treated with extracranial-intracranial arterial bypass and Drake tourniquet. Surg Neurol 22: 33-35, 1984

25) van Doormaal TP, van der Zwan A, Verweij BH, Han KS, Langer DJ, Tulleken CA: Treatment of giant middle cerebral artery aneurysms with a flow replacement bypass using the excimer laser-assisted nonocclusive anastomosis technique. Neurosurgery 63: 12-22, 2008

Address reprint requests to: Hideki Nakajima, MD, Department of Neurosurgery, Osaka City General Hospital, 2-13-22 Miyakojima-Hondori, Miyakojima-ku, Osaka 534-0021, Japan.

e-mail: h-nakajima@hospital.city.osaka.jp 